Pacific Journal of Mathematics

A COMMUTATIVE BANACH ALGEBRA OF FUNCTIONS OF 


\title{
A COMMUTATIVE BANACH ALGEBRA OF FUNCTIONS OF GENERALIZED VARIATION
}

\author{
A. M. RUSSELL
}

It is known that the space of functions, anchored at $a$, and having bounded variation form a commutative Banach algebra under the total variation norm. We show that functions of bounded $k$ th variation also form a Banach algebra under a norm defined in terms of the total $k$ th variation.

1. Introduction. Let $B V_{1}[a, b]$ denote the space of functions of bounded variation on the closed interval $[a, b]$, and denote the total variation of $f$ on that interval by $V_{1}(f)$ or $V_{1}(f ; a, b)$. If

$$
B V_{1}^{*}[a, b]=\left\{f ; V_{1}(f)<\infty, f(a)=0\right\},
$$

then it is a well known result that $B V_{1}^{*}[a, b]$ is a Banach space under the norm $\|\cdot\|_{1}$, where $\|f\|_{1}=V_{1}(f)$. What appears to be less well known is that, using pointwise operations, $B V_{1}^{*}[a, b]$ is a commutative Banach algera with a unit under $\|\cdot\|_{1}$ - see for example [1] and Exercise 17.35 of [2].

In [4] it was shown that $B V_{k}[a, b]$ is a Banach space under the norm, $\|\cdot\|_{k}$, where

$$
\|f\|_{k}=\sum_{s=0}^{k-1}\left|f^{(s)}(a)\right|+V_{k}(f ; a, b),
$$

and where the definition of $V_{k}(f ; a, b) \equiv V_{k}(f)$ can be found in [3]. The subspace

$$
B V_{l_{*}^{*}}^{*}[a, b]=\left\{f ; f \in B V_{k}[a, b], f(a)=f^{\prime}(a)=\cdots=f^{(k-1)}(a)=0\right\}
$$

is clearly also a Banach space under the norm $\|\cdot\|_{k}^{*}$, where

$$
\|f\|_{k}^{*}=\alpha_{k} V_{k}(f),
$$

and $\alpha_{k}=2^{k-1}(b-a)^{k-1}(k-1) !$.

If we define the product of two functions in $B V_{k}^{*}[a, b]$ by pointwise multiplication, then we show, in addition, that $B V_{k}^{*}[a, b]$ is a commutative Banach algebra under the norm given in (2). It is obvious that $B V_{k}^{*}[a, b]$ is commutative, so our main programme now is to show that if $f$ and $g$ belong to $B V_{k}^{*}[a, b]$, then so does $f g$, and that

$$
V_{k}(f g) \leqq 2^{k-1}(k-1) !(b-a)^{k-1} V_{k}(f) V_{k}(g), \quad k \geqq 1 .
$$


We accept the case $k=1$ as being known, so restrict our discussion to $k \geqq 2$. Because the same procedure does not appear to be applicable to the cases $k=2$ and $k \geqq 3$, we present different treatments for these cases.

In order to achieve the stated results it was found convenient to work with two definitions of bounded $k$ th variation, one defined with quite arbitrary subdivisions $a=x_{0}, x_{1}, \cdots, x_{n}=b$ of $[a, b]$, and the other using subdivisions in which all sub-intervals are of equal length. If we call the two classes of functions so obtained $B V_{k}[a, b]$ and $\overline{B V_{k}}[a, b]$ respectively, then we show that provided we restrict our functions to being continuous, then these classes are identical. More specifically, if we denote $C[a, b], B V_{k}[a, b]$, and $\overline{B V}_{k}[a, b]$ by $C, B V_{k}$ and $\overline{B V}_{k}$ respectively, then we show that

$$
C \cap B V_{k}=\overline{B V}_{k} \text {. }
$$

\section{Notation and preliminaries.}

Definition 1. We shall say that a set of points $x_{0}, x_{1}, \cdots, x_{n}$ is a $\pi$-subdivision of $[a, b]$ when $a \leqq x_{0}<x_{1}<\cdots<x_{n}=b$.

Definition 2. If $h>0$, then we will denote by $\pi_{h}$ a subdivision $x_{0}, x_{1}, \cdots, x_{n}$ of $[a, b]$ such that $a=x_{0}<x_{1}<\cdots<x_{n} \leqq b$, where $x_{i}-x_{i-1}=h, i=1,2, \cdots, n$, and $0 \leqq b-x_{n} \leqq h$.

Before introducing the two definitions of bounded leth variation we need the definition and some properties of $k$ th divided differences, and for this purpose we refer the reader to [3]. In addition, we make use of the difference operator $\Delta_{h}^{k}$ defined by

$$
\Delta_{h}^{1} f(x)=f(x+h)-f(x),
$$

and

$$
\Delta_{h}^{k} f(x)=\Delta_{h}^{1}\left[\Delta_{h}^{k-1} f(x)\right]
$$

Definition 3. The total kth variation of a function $f$ on $[a, b]$ is defined by

$$
V_{k}(f ; a, b)=\sup _{\pi} \sum_{i=0}^{n-k}\left(x_{i+k}-x_{i}\right)\left|Q_{k}\left(f ; x_{i}, \cdots, x_{i+k}\right)\right| .
$$

If $V_{k}(f ; a, b)<\infty$, we say that $f$ is of bounded $k$ th variation on $[a, b]$, and write $f \in B V_{k}[a, b]$.

Definition 4. If $f$ is continuous on $[a, b]$, then we define the total $k$ th variation of $f$ on $[a, b]$ (restricted form) by 


$$
\bar{V}_{k}(f ; a, b)=\sup _{\pi_{h}} \sum_{i=0}^{n-k}\left|\frac{\Delta_{h}^{k} f\left(x_{i}\right)}{h^{k-1}}\right|
$$

If $\bar{V}_{k}(f ; a, b)<\infty$, we say that $f$ is of restricted bounded $k$ th variation on $[a, b]$, and write $f \in \overline{B V}_{k}[a, b]$.

As before, we will usually write $V_{k}(f)$ and $\bar{V}_{k}(f)$ for $V_{k}(f ; a, b)$ and $\bar{V}_{k}(f ; a, b)$ respectively.

We now show that $C \cap B V_{k}=\overline{B V}_{k}$, and point out at this stage that the restriction to continuous functions is not nearly as severe as it first may appear, because functions belonging to $B V_{k}[a, b]$, when $k \geqq 2$, are automatically continuous - see Theorem 4 of [3].

LEMMA 1. Let $I_{1}, I_{2}, \cdots, I_{n}$ be a set of $n$ adjoining closed intervals on the real line having lengths $p_{1} / q_{1}, p_{2} / q_{2}, \cdots, p_{n} / q_{n}$ respectively, where $p_{1}, p_{2}, \cdots, p_{n}, q_{1}, q_{2}, \cdots, q_{n}$ are positive integers. Then it is possible to subdivide the intervals $I_{1}, I_{2}, \cdots, I_{n}$ into sub-intervals of equal length.

The proof is easy and will be omitted.

LEMmA 2. If $k \geqq 1$, then $C \cap B V_{k} \subset \overline{B V}_{k}$, using abbreviated notation.

Proof. This is easy and will not be included.

Lemma 3. If $k \geqq 1$, then $C \cap B V_{k} \supset \overline{B V}_{k}$.

Proof. Let us suppose that $f$ is continuous, belongs to $\overline{B V_{k}}[a, b]$, but $f \notin B V_{k}[a, b]$. Then for an arbitrarily large number $K$, and an arbitrarily small positive number $\varepsilon$, there exists a subdivision $\pi_{1}\left(x_{0}, x_{1}, \cdots, x_{n}\right)$ of $[a, b]$ such that

$$
S_{\pi_{1}} \equiv \sum_{i=0}^{n-k}\left(x_{i+k}-x_{i}\right)\left|Q_{k}\left(f ; x_{i}, \cdots, x_{i+k}\right)\right|>K+\varepsilon .
$$

If not all the lengths $\left(x_{i+1}-x_{i}\right), i=0,1, \cdots, n-1$ are rational, then because $f$ is continuous we can obtain a subdivision $\pi_{2}\left(y_{0}, y_{1}\right.$, $\left.\cdots, y_{n}\right)$ of $[a, b]$ in which all the lengths $\left(y_{i+1}-y_{i}\right), i=0,1, \cdots, n-1$ are rational, and such that $\left|S_{\pi_{1}}-S_{\pi_{2}}\right|<\varepsilon, S_{\pi_{2}}$ being the approximating sum of $V_{k}(f ; a, b)$ corresponding to the $\pi_{2}$ subdivision. Consequently,

$$
S_{\pi_{2}} \geqq S_{\pi_{1}}-\left|S_{\pi_{1}}-S_{\pi_{2}}\right|>K
$$

In the $\pi_{2}$ subdivision, all sub-intervals have rational length, so we can apply Lemma 1 to obtain a $\pi_{h}$ subdivision of $[a, b]$ in which each 
sub-interval has length $h$. If $S_{\pi_{h}}$ is the corresponding approximating sum of $\bar{V}_{k}(f ; a, b)$, then it follows from Theorem 3 of [3] that

$$
\frac{1}{(k-1) !} S_{\pi_{h}} \geqq S_{\pi_{2}}>K
$$

since for any $\pi_{h}$ subdivision, and each $i=0,1, \cdots, n-k$,

$$
\frac{\Delta_{h}^{k} f\left(x_{i}\right)}{h^{k-1}}=(k-1) !\left(x_{i+k}-x_{i}\right) Q_{k}\left(f ; x_{i}, \cdots, x_{i+k}\right) \text {. }
$$

Thus $S_{\pi_{h}}>(k-1) ! K$, and this is a contradiction to the assumption that $f \in \overline{B V}_{k}[a, b]$. Hence $f \in \overline{B V}_{k}[a, b]$, and so $\overline{B V}_{k} \subset C \cap B V_{k}$.

THEOREM 1. If $k \geqq 1$, then $C \cap B V_{k}=\overline{B V}_{k}$; and if $f$ is a continuous function on $[a, b]$, then

$$
\bar{V}_{k}(f ; a, b)=(k-1) ! V_{k}(f ; a, b), \quad k \geqq 1 .
$$

Proof. The first part follows from Lemmas 2 and 3. For the second part we first observe that

$$
\bar{V}_{k}(f ; a, b) \leqq(k-1) ! V_{k}(f ; a, b) .
$$

Let $\varepsilon>0$ be arbitrary. Then there exists a $\pi_{1}$ subdivision of $[a, b]$ and the corresponding approximating sum $S_{\pi_{1}}$ to $V_{k}(f ; a, b)$ such that

$$
S_{\pi_{1}}>V_{k}(f ; a, b)-\frac{\varepsilon}{2(k-1) !} .
$$

If not all the sub-intervals of $\pi_{1}$ have rational lengths, then we can proceed as in Lemma 3 to obtain a $\pi_{h}$ subdivision of $[a, b]$ in which all sub-intervals are of equal length $h$. Then, if $S_{\pi_{h}}$ is the corresponding approximating sum to $\bar{V}_{k}(f ; a, b)$, we can show that

$$
\begin{aligned}
\frac{1}{(k-1) !} S_{\pi_{h}} & \geqq S_{\pi_{1}}-\frac{\varepsilon}{2(k-1) !} \\
& >V_{k}(f ; a, b)-\frac{\varepsilon}{(k-1) !} .
\end{aligned}
$$

Consequently,

$$
\begin{aligned}
\bar{V}_{k}(f ; a, b) & \geqq S_{\pi_{h}} \\
& >(k-1) ! V_{k}(f ; a, b)-\varepsilon,
\end{aligned}
$$

from which it follows that $\bar{V}_{k}(f ; a, b) \geqq(k-1) ! V_{k}(f ; a, b)$. This inequality together with (4) gives (3). 
LEMMA 4. If $f$ and $g$ are any two real valued functions defined on $[a, b], h>0$ and $a \leqq x<x+k h \leqq b$, then

$$
\begin{array}{r}
\Delta_{h}^{k}[f(x) g(x)]=f(x+k h) \Delta_{h}^{k} g(x)+\left(\begin{array}{c}
k \\
1
\end{array}\right) \Delta_{h}^{1} f(x+(k-1) h) \Delta_{h}^{k-1} g(x)+\cdots \\
+\left(\begin{array}{c}
k \\
s
\end{array}\right) \Delta_{h}^{s} f(x+(k-s) h) \Delta_{h}^{k-s} g(x)+\cdots+\Delta_{h}^{k} f(x) \Delta_{h}^{0} g(x) \\
=\sum_{s=i}^{k}\left(\begin{array}{l}
k \\
s
\end{array}\right) \Delta_{h}^{s} f(x+(k-s) h) \Delta_{h}^{k-s} g(x), \text { where } \Delta_{h}^{0} g(x)=g(x) .
\end{array}
$$

Proof. The proof by induction is straightforward and will not be included.

Lemma 5. If $f$ and $g$ belong to $B V_{k}[a, b], k \geqq 1$, then $f g \in B V_{k}[a, b]$.

Proof. The result for $k=1$ is well known, so we assume that $k \geqq 2$, in which case $f$ and $g$ are continuous in $[a, b]$. Consequently, in view of Theorem 1 , there will be no loss of generality in working with equal sub-intervals of $[a, b]$. Using (5) we have, suppressing the " $h$ " in " $\Delta_{h}^{k}$ ",

$$
\begin{gathered}
\frac{\Delta^{k}[f(x) g(x)]}{h^{k-1}}=f(x+k h) \frac{\Delta^{k} g(x)}{h^{k-1}}+\cdots+\left(\begin{array}{c}
k \\
s
\end{array}\right) \frac{\Delta^{s} f(x+(k-s) h)}{h^{s}} \frac{\Delta^{k-s} g(x)}{h^{k-s-1}} \\
+\cdots+\frac{\Delta^{k-1} f(x+h)}{h^{k-1}} \Delta^{1} g(x)+\frac{\Delta^{k} f(x)}{h^{k-1}} g(x) .
\end{gathered}
$$

It follows from Theorem 4 of [3] that

$$
\frac{\Delta^{s} f(x+(k-s) h)}{h^{s}}, s=0,1, \cdots, k-1
$$

is uniformly bounded. Hence we can conclude from (6) that $f g \in$ $\overline{B V}_{k}[a, b]$ by summing over any $\pi_{h}$ subdivision of $[a, b]$, and noting that $f$ and $g$ belong to $\overline{B V}_{k}[a, b] \subset \overline{B V}_{k-1}[a, b] \subset \cdots \subset \overline{B V}_{1}[a, b]-$ see Theorem 10 of [3]. Since $f g$ is continuous it follows from Theorem 1 that $f g \in B V_{k}[a, b]$.

3. Main results. We now make an application of Theorem 1 to obtain a relationship between $V_{k-1}(f)$ and $V_{k}(f)$ when $f \in B V_{k}^{*}[a, b]$.

THEOREM 2. If $f \in B V_{k}^{*}[a, b], k \geqq 2$, then

$$
V_{k-1}(f) \leqq(k-1)(b-a) V_{k}(f),
$$


or

$$
\bar{V}_{k-1}(f) \leqq(b-a) \bar{V}_{k}(f)
$$

Proof. It follows from Theorem 10 of [3] that $f \in B V_{k-1}^{*}[a, b]$, so $V_{k-1}(f)<\infty$. We now establish the inequality. Since $f \in B V_{k}^{*}[a, b]$, $f^{(k-1)}(a)=0$. Hence for any $\varepsilon>0$, we can choose a $\pi_{h}$ subdivision of $[a, b]$ such that

$$
\left|\frac{\Delta_{h}^{k-1} f(a)}{h^{k-1}}\right|<\frac{\varepsilon}{(b-a)} .
$$

There is no loss of generality in choosing such a subdivision in view of Theorem 3 of [3] which tells us that the approximating sums for total $k$ th variation are not decreased by the addition of extra points of subdivision. Accordingly, let $a=x_{0}, x_{1}, \cdots, x_{n} \leqq b$ be a $\pi_{h}$ subdivision of $[a, b]$ with property (8). Then, suppressing the " $h$ " in " $\Delta_{h}^{k-1}$ " and " $\Delta_{h}^{k}$ ", we obtain

$$
\begin{aligned}
\sum_{i=0}^{n-k+1}\left|\Delta^{k-1} f\left(x_{i}\right)\right| & =\sum_{i=0}^{n-k+1}\left|\sum_{s=1}^{i}\left[\Delta^{k-1} f\left(x_{s}\right)-\Delta^{k-1} f\left(x_{s-1}\right)\right]+\Delta^{k-1} f\left(x_{0}\right)\right| \\
& =\sum_{i=0}^{n-k+1}\left|\sum_{s=1}^{i} \Delta^{k} f\left(x_{s-1}\right)+\Delta^{k-1} f\left(x_{0}\right)\right| \\
& \leqq \sum_{i=0}^{n-k+1} \sum_{s=1}^{i}\left|\Delta^{k} f\left(x_{s-1}\right)\right|+\sum_{i=0}^{n-k+1}\left|\Delta^{k-1} f\left(x_{0}\right)\right| \\
& \leqq n \sum_{s=1}^{n-k}\left|\Delta^{k} f\left(x_{s-1}\right)\right|+n\left|\Delta^{k-1} f\left(x_{0}\right)\right| \\
& \leqq(b-a) \sum_{s=1}^{n-k}\left|\frac{\Delta^{k} f\left(x_{s-1}\right)}{h}\right|+(b-a)\left|\frac{\Delta^{k-1} f\left(x_{0}\right)}{h}\right|
\end{aligned}
$$

Therefore, dividing both sides by $h^{k-2}$, we obtain

$$
\begin{aligned}
\sum_{i=0}^{n-k+1}\left|\frac{\Delta^{k-1} f\left(x_{i}\right)}{h^{k-2}}\right| & \leqq(b-a) \sum_{s=1}^{n-k}\left|\frac{\Delta^{k} f\left(x_{s-1}\right)}{h^{k-1}}\right|+(b-a)\left|\frac{\Delta^{k-1} f\left(x_{0}\right)}{h^{k-1}}\right| \\
& \leqq(b-a) \bar{V}_{k}(f)+\varepsilon,
\end{aligned}
$$

from which it follows that

$$
\bar{V}_{k-1}(f) \leqq(b-a) \bar{V}_{k}(f) .
$$

Consequently, using (2) we obtain

$$
V_{k-1}(f) \leqq(k-1)(b-a) V_{k}(f),
$$

as required.

Corollary. Let $p$ be an integer such that $1 \leqq p<k$. If $f \in$ $B V_{l k}^{*}[a, b]$, then $f \in B V_{p}^{*}[a, b]$, and 


$$
V_{p}(f) \leqq p(p+1) \cdots(k-1)(b-a)^{k-p} V_{k}(f)
$$

or

$$
\bar{V}_{p}(f) \leqq(b-a)^{k-p} \bar{V}_{k}(f) \text {. }
$$

Proof. The proof follows from repeated applications of (7), and Theorem 10 of [3].

We now proceed to obtain a relationship between $V_{k}(f g), V_{k}(f)$ and $V_{k}(g)$ when $f$ and $g$ belong to $B V_{k}^{*}[a, b]$. It appears convenient to treat the cases $k=2$, and $k \geqq 3$ separately, so we begin by considering $k=2$.

THEOREM 3. If $f$ and $g$ belong to $B V_{2}^{*}[a, b]$, then $f g \in B V_{2}^{*}[a, b]$, and

$$
\begin{aligned}
V_{2}(f g) & \leqq V_{2}(f) V_{1}(g)+V_{1}(f) V_{2}(g) \\
& \leqq 2(b-a) V_{2}(f) V_{2}(g)
\end{aligned}
$$

Proof. There is no loss of generality in considering $\pi_{h}$ subdivisions of $[a, b]$. Let $a=x_{0}, x_{1}, \cdots, x_{n}$ be such a subdivision. Then, noting that $f(a)=0=g(a)$ when $f, g \in B V_{2}^{*}[a, b]$, and writing $f\left(x_{s+1}\right)-f\left(x_{s}\right)=\Delta f\left(x_{s}\right)$, we obtain for $i \geqq 1$,

$$
\begin{aligned}
\Delta^{2} f\left(x_{i}\right) g\left(x_{i}\right)= & \Delta\left[\Delta f\left(x_{i}\right) g\left(x_{i}\right)\right] \\
= & \Delta\left[f\left(x_{i+1}\right) \Delta g\left(x_{i}\right)+\left(\Delta f\left(x_{i}\right)\right) g\left(x_{i}\right)\right] \\
= & \Delta\left[\left(\sum_{s=0}^{i} \Delta f\left(x_{s}\right)\right) \Delta g\left(x_{i}\right)+\Delta f\left(x_{i}\right) \sum_{s=0}^{i-1} \Delta g\left(x_{s}\right)\right] \\
= & \sum_{s=0}^{i} \Delta\left(\Delta f\left(x_{s}\right) \Delta g\left(x_{i}\right)\right)+\sum_{s=0}^{i-1} \Delta\left(\Delta f\left(x_{i}\right) \Delta g\left(x_{s}\right)\right) \\
= & \sum_{s=0}^{i}\left[\Delta f\left(x_{s+1}\right) \Delta^{2} g\left(x_{i}\right)+\Delta^{2} f\left(x_{s}\right) \Delta g\left(x_{i}\right)\right] \\
& +\sum_{s=0}^{i-1}\left[\Delta f\left(x_{i+1}\right) \Delta^{2} g\left(x_{s}\right)+\Delta^{2} f\left(x_{i}\right) \Delta g\left(x_{s}\right)\right] .
\end{aligned}
$$

Therefore, noting that the last summation in (12) is zero when $i=0$, we have

$$
\begin{aligned}
\sum_{i=0}^{n-2}\left|\Delta^{2} f\left(x_{i}\right) g\left(x_{i}\right)\right| & \leqq \sum_{i=0}^{n-2}\left[\left|\Delta f\left(x_{1}\right)\right|+\cdots+\left|\Delta f\left(x_{i+1}\right)\right|\right]\left|\Delta^{2} g\left(x_{i}\right)\right| \\
& +\sum_{i=0}^{n-2}\left[\left|\Delta^{2} f\left(x_{0}\right)\right|+\cdots+\left|\Delta^{2} f\left(x_{i}\right)\right|\right] \Delta g\left(x_{i}\right) \mid \\
& +\sum_{i=0}^{n-2}\left|\Delta f\left(x_{i+1}\right)\right|\left[\left|\Delta^{2} g\left(x_{0}\right)\right|+\cdots+\left|\Delta^{2} g\left(x_{i-1}\right)\right|\right] \\
& +\sum_{i=1}^{n-2}\left|\Delta^{2} f\left(x_{i}\right)\right|\left[\Delta g\left(x_{0}\right)|+\cdots+| \Delta g\left(x_{i-1}\right) \mid\right],
\end{aligned}
$$


which after some re-arrangement is equal to

$$
\left(\sum_{i=1}^{n-1}\left|\Delta f\left(x_{i}\right)\right|\right)\left(\sum_{i=0}^{n-2}\left|\Delta^{2} g\left(x_{i}\right)\right|\right)+\left(\sum_{i=0}^{n-2}\left|\Delta^{2} f\left(x_{i}\right)\right|\right)\left(\sum_{i=0}^{n-2}\left|\Delta g\left(x_{i}\right)\right|\right) .
$$

Therefore, dividing by $h$, and using Definition 4 , we observe that $f g \in B V_{2}^{*}[a, b]$, and obtain

$$
\bar{V}_{2}(f g) \leqq \bar{V}_{1}(f) \bar{V}_{2}(g)+\bar{V}_{2}(f) \bar{V}_{1}(g),
$$

or

$$
V_{2}(f g) \leqq V_{1}(f) V_{2}(g)+V_{2}(f) V_{1}(g),
$$

using Theorem 1.

To complete the proof we employ (7) with $k=2$.

We are now in a position to consider the general case $k \geqq 3$ for which we adopt a different procedure. When $k \geqq 3$ we make use of the fact that $f^{(k-2)} \in B V_{2}^{*}[a, b]$, and consequently exists throughout $[a, b]$, and is in fact absolutely continuous in that interval.

THEOREM 4. Let $f$ and $g$ belong to $B V_{k}^{*}[a, b]$ when $k \geqq 3$. Then $f g \in B V_{k}^{*}[a, b]$, and

$$
\bar{V}_{k}(f g) \leqq 2^{k-1}(b-a)^{k-1} \bar{V}_{k}(f) \bar{V}_{k}(g),
$$

or

$$
V_{k}(f g) \leqq 2^{k-1}(b-a)^{k-1}(k-1) ! V_{k}(f) V_{k}(g)
$$

Proof. We first observe from Lemma 5 that $f g \in B V_{k}^{*}[a, b]$. It follows from Theorems 2 and 8 of [5] that

$$
\begin{aligned}
& \bar{V}_{k}(f g)=\bar{V}_{2}\left((f g)^{(k-2)}\right) \\
& =\bar{V}_{2}\left(\sum_{s=0}^{k-2}\left(\begin{array}{c}
k-2 \\
s
\end{array}\right) f^{(k-s-2)} g^{(s)}\right) \\
& \leqq \sum_{s=0}^{k-2}\left(\begin{array}{c}
k-2 \\
s
\end{array}\right) \bar{V}_{2}\left(f^{(k-s-2)} g^{(s)}\right) \\
& \leqq 2(b-a) \sum_{s=0}^{k-2}\left(\begin{array}{c}
k-2 \\
s
\end{array}\right) \bar{V}_{2}\left(f^{(k-s-2)}\right) \bar{V}_{2}\left(g^{(s)}\right) \text {, using } \\
& =2(b-a) \sum_{s=0}^{k-2}\left(\begin{array}{c}
k-2 \\
s
\end{array}\right) \bar{V}_{k-s}(f) \bar{V}_{s+2}(g) \\
& \leqq 2(b-a) \sum_{s=0}^{k-2}\left(\begin{array}{c}
k-2 \\
s
\end{array}\right)(b-a)^{s} \bar{V}_{k}(f) \cdot(b-a)^{k-s-2} \bar{V}_{k}(g),
\end{aligned}
$$




$$
\begin{aligned}
& =2(b-a)^{k-1} \bar{V}_{k}(f) \bar{V}_{k}(g) \sum_{s=0}^{k-2}\left(\begin{array}{c}
k-2 \\
s
\end{array}\right) \\
& =2^{k-1}(b-a)^{k-1} \bar{V}_{k}(f) \bar{V}_{k}(g) \text {, as required for (14). }
\end{aligned}
$$

To obtain (15) we employ (3).

Combining Theorems 3 and 4 gives

THEOREM 5. If $f$ and $g$ belong to $B V_{k}^{*}[a, b], k \geqq 1$, then $f g \in B V_{k}^{*}[a, b]$, and

$$
V_{k}(f g) \leqq \alpha_{k} V_{k}(f) V_{k}(g),
$$

where $\alpha_{k}=2^{k-1}(k-1) !(b-1)^{k-1}$.

Our final theorem is now apparent.

THEOREM 6. If $k$ is a positive integer, then $B V_{k}^{*}[a, b]$ is a commutative Banach algebra under the norm $\|\cdot\|_{k}^{*}$, where

$$
\|f\|_{k}^{*}=\alpha_{k} V_{k}(f),
$$

and $\alpha_{k}=2^{k-1}(k-1) !(b-a)^{k-1}$.

\section{REFERENCES}

1. G. Dickmeis and W. Dickmeis, Beste Approximation in Räumen von beschränkter p-Variation, Forschungberichte Des Landes Nordrhein-Westfalen Nr. 2697 Fachgruppe Mathematik/Informatik, Westdeutscher Verlag, 1977.

2. E. Hewitt and K. Stromberg, Real and Abstract Analysis, Springer-Verlag, Berlin, Heidelberg, New York, 1969.

3. A. M. Russell, Functions of bounded kth variation, Proc. London Math. Soc., (3) 26 547-563.

4. — A Banach space of functions of generalized variation, Bull. Austral. Math. Soc., Vol. 15 (1976), 431-438.

5. - Further results on an integral representation of functions of generalized variation, Bull. Austral. Math. Soc., 18 (1978), 407-420.

Received June 1, 1978.

University of Melbourne

PARKVILLE, Victoria 3052

AUSTRalia 



\section{PACIFIC JOURNAL OF MATHEMATICS}

\section{EDITORS}

DONALD BABBITT (Managing Editor)

University of California

Los Angeles, CA 90024

HUGO RossI

University of Utah

Salt Lake City, UT 84112

C. C. Moore and ANDrew OGG

University of California

Berkeley, CA 94720
J. DUGUNDJI

Department of Mathematics University of Southern California Los Angeles, CA 90007

R. FINN and J. MILGRAM

Stanford University

Stanford, CA 94305

\section{ASSOCIATE EDITORS}
E. F. BeCKENBACH
B. H. NeumanN
F. WOLF
K. YOSHIDA

\section{SUPPORTING INSTITUTIONS}

UNIVERSITY OF BRITISH COLUMBIA CALIFORNIA INSTITUTE OF TECHNOLOGY UNIVERSITY OF CALIFORNIA MONTANA STATE UNIVERSITY UNIVERSITY OF NEVADA, RENO NEW MEXICO STATE UNIVERSITY OREGON STATE UNIVERSITY UNIVERSITY OF OREGON

\author{
UNIVERSITY OF SOUTHERN CALIFORNIA \\ STANFORD UNIVERSITY \\ UNIVERSITY OF HAWAII \\ UNIVERSITY OF TOKYO \\ UNIVERSITY OF UTAH \\ WASHINGTON STATE UNIVERSITY \\ UNIVERSITY OF · WASHINGTON
}

The Supporting Institutions listed above contribute to the cost of publication of this Journal, but they are not owners or publishers and have no responsibility for its content or policies.

Mathematical papers intended for publication in the Pacific Journal of Mathematics should be in typed form or offset-reproduced, (not dittoed), double spaced with large margins. Please do not use built up fractions in the text of the manuscript. However, you may use them in the displayed equations. Underline Greek letters in red, German in green, and script in blue. The first paragraph or two must be capable of being used separately as a synopsis of the entire paper. Please propose a heading for the odd numbered pages of less than 35 characters. Manuscripts, in triplicate, may be sent to any one of the editors. Please classify according to the scheme of Math. Reviews, Index to Vol. 39. Supply name and address of author to whom proofs should be sent. All other communications should be addressed to the managing editor, or Elaine Barth, University of California, Los Angeles, California, 90024.

50 reprints to each author are provided free for each article, only if page charges have been substantially paid. Additional copies may be obtained at cost in multiples of 50 .

The Pacific Journal of Mathematics is issued monthly as of January 1966. Regular subscription rate: $\$ 84.00$ a year (6 Vols., 12 issues). Special rate: $\$ 42.00$ a year to individual members of supporting institutions.

Subscriptions, orders for numbers issued in the last three calendar years, and changes of address should be sent to Pacific Journal of Mathematics, P.O. Box 969, Carmel Valley, CA 93924, U.S.A. Older back numbers obtainable from Kraus Periodicals Co., Route 100, Millwood, NY 10546.

PUBLISHED BY PACIFIC JOURNAL OF MATHEMATICS, A NON-PROFIT CORPORATION

Printed at Kokusai Bunken Insatsusha (International Academic Printing Co., Ltd.). 8-8, 3-chome, Takadanobaba, Shinjuku-ku, Tokyo 160, Japan.

Copyright (C) 1979 by Pacific Journal of Mathematics Manufactured and first issued in Japan 


\section{Pacific Journal of Mathematics}

\section{Vol. 84, No. $2 \quad$ June, 1979}

Somesh Chandra Bagchi and Alladi Sitaram, Spherical mean periodic

functions on semisimple Lie groups ........................ 241

Billy Joe Ball, Quasicompactifications and shape theory............. 251

Maureen A. Bardwell, The o-primitive components of a regular ordered permutation group ................................ 261

Peter W. Bates and James R. Ward, Periodic solutions of higher order

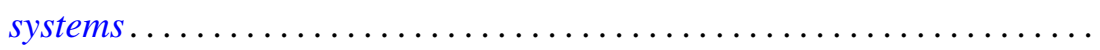

Jeroen Bruijning, A characterization of dimension of topological spaces by totally bounded pseudometrics......................... 283

Thomas Farmer, On the reduction of certain degenerate principal series

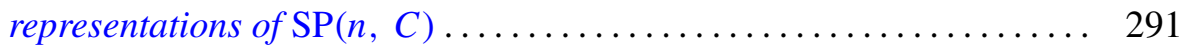

Richard P. Jerrard and Mark D. Meyerson, Homotopy with m-functions . . . . 305

James Edgar Keesling and Sibe Mardesic, A shape fibration with fibers of

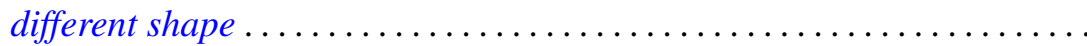

Guy Loupias, Cohomology over Banach crossed products. Application to bounded derivations and crossed homomorphisms ...............

Rainer Löwen, Symmetric planes ........................ 367

Alan L. T. Paterson, Amenable groups for which every topological left

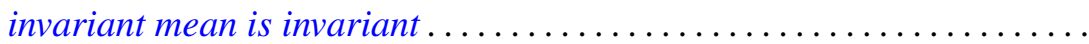

Jack Ray Porter and R. Grant Woods, Ultra-Hausdorff H-closed extensions

Calvin R. Putnam, Operators satisfying a $G_{1}$ condition .

Melvin Gordon Rothenberg and Jonathan David Sondow, Nonlinear smooth representations of compact Lie groups..............

Werner Rupp, Riesz-presentation of additive and $\sigma$-additive set-valued measures.

A. M. Russell, A commutative Banach algebra of functions of generalized variation

Judith D. Sally, Superregular sequences

Patrick Shanahan, On the signature of Grassmannians . . 